8

\title{
METAMORFOSIS DE LO ORIGINARIO*
}

\section{(CODAS DEL INFORME)}

"Si el receptor del texto originario articula el resultado de su elaboración en un nuevo texto, entonces ha tenido lugar la [operación de] transducción: un nuevo texto, una metamorfosis del original..." L. Dôlezel

Tradizione e progresso 


\section{CONCLUSIONES DEL INFORME}

1.0. El abordaje de los fenómenos de transducción (transposición, traslado, traspaso, transfiguración) textual demanda recrear o reformular categorías analíticas e interpretativas disponibles, a fin de poder dar cuenta de las significativas interrelaciones y complementariedades que vinculan $y$, a veces, anudan los procedimientos de la discursividad verbal con los recursos expresivos y mecanismos constructivos propios de otros códigos y lenguajes: audiovisuales, espectaculares, teatrales, fílmicos, hipermediales, etc.

Si a la vez se comprende que un adecuado tratamiento teórico-crítico de dicha cuestión (en el específico ámbito artístico, al menos) exige problematizar los cruces, desacomodos y negociaciones que caracterizan los circuitos de producción (política, ideología) y de consumo (economía, mercado) de las llamadas industrias culturales... se puede concluir en que, lo efectivamente productivo del análisis de esa trama o tejido de significados interdependientes (de estas formaciones discursivas, en términos de Foucault), se encuentra más bien en los sentidos y efectos de la operación de transducción, antes que en las eventuales coincidencias, similitudes o desvíos observables en los resultados de la misma.

De ahí que resulten insuficientes, cuando no reductivas o inapropiadas, las denominaciones habituales (versión, adaptación, etc.) con que se suelen designar ${ }^{1}$ estos fenómenos de relación intersemiótica y de mutua implicación cotextual. Porque, en vez de implicar planteamientos unilaterales, debieran enfatizar las

\footnotetext{
${ }^{1}$ Respecto del generalizado empleo de la noción de adaptación, un crítico español argumenta que dicho concepto es "semiológica y artísticamente insostenible... [ya que], por mucha fidelidad con que se haya resuelto la operación [de traducir una historia plasmada en discurso verbal, al lenguaje audiovisual], y aunque la sustancia del contenido argumental haya experimentado mínimas alteraciones, el significado final de la segunda obra de arte es inexorablemente distinta al de la primera. Hay pues un margen de complementariedad y no de redundancia, que el público percibe como tal." (Villanueva, 1992: 28).
} 
zonas de cruce e intersección de ambos objetos ${ }^{2}$, las que se registran a través de diferentes modos de lectura y cuyas operatorias analíticas e interpretativas "se orientan más al sistema de llegada que al de partida"... Porque sin perjuicio de los "contenidos (efectivamente) transferidos", importa testimoniar la complejidad dialéctica de un nuevo producto resultante de "la obra [original], el contexto sociohistórico y los códigos de una cultura" (Bowie, 2003: 12-18)

1.1. Relacionado con las maneras de instrumentar y operacionalizar estas problemáticas ( $y$, en breve, con sus posibilidades -concretas, puntuales- de aprovechamiento para una efectiva mejora de las prácticas de investigación y de enseñanza), en el presente informe de avance se reformularon los lineamientos básicos originales de una investigación narrativa aplicada al campo artístico espectacular (que vengo desarrollando hace dos años), y se reseñaron algunos resultados obtenidos a través del desenvolvimiento de un estudio exploratorio (realizado durante el último año). Se abordaron, en el primer caso, las principales bases y orientaciones teórico-metodológicas del estudio en ejecución: se fundamentaron la especificidad y pertinencia del trayecto investigativo (en relación con el proyecto general al que pertenece), se enunciaron los propósitos particulares de dicha indagación, se explicitaron presupuestos o hipótesis iniciales de trabajo, se caracterizó el corpus analítico previamente diseñado, se señalaron algunas dificultades y alternativas de solución (consideradas e implementadas), etc.

\footnotetext{
${ }^{2}$ Coincido con L. Scarano cuando dice que "estudiar este vaivén - de la letra a la imagen- significa además advertir que la supuesta cristalización de componentes narrativos operados por las imágenes fílmicas responde a un hábito cultural, una práctica de recepción estética que otorgaría un mayor grado de connotación a la escritura, restando potencial a su contraparte visual. Todavía hoy somos espectadores del 'mayor aura' que la doxa otorga a una obra literaria frente a su versión fílmica; pero ya vamos asistiendo a la declinación de esa supuesta 'superioridad', en manos de nuevas generaciones que operan una profunda revisión de estos cánones académicos consagrados" (Scarano en Ferrari, 2007: 28)
} 
En cuanto a la segunda parte del informe, se expusieron seis propuestas de lectura (sustentadas en sus correspondientes marcos y registros teóricos y metodológicos) aplicadas al texto dramático Un guapo del 900 (1940) de Samuel Eichelbaum: tres recorridos explicativos fundados en la segmentación textual y discursiva de la obra, dos abordajes cotextuales que aproximan cuestiones de matriz ideológica e histórico-política, y una lectura complementaria que introduce aspectos preliminares de su transposición al cine.

Este primer relevamiento del texto originario de una serie textual se complementará (en la siguiente instancia de ejecución del estudio) con una detenida confrontación relacional de permanencias, cambios y transformaciones operadas en dos transposiciones fílmicas de la misma obra, respectivamente dirigidas por Leopoldo Torre Nilsson (1960) y por Lautaro Murúa (1971), con el propósito de someter a prueba experimental categorías, mecanismos y procedimientos de transducción semiótica.

1.2. Tres principios constructivos básicos del contenido y la expresión del texto dramático Un guapo del 900 de Eichelbaum permiten reordenar la lectura del material pre-espectacular: (a) una concepción orgánica y sincrética del conjunto escénico, dado a través de diversas componentes que concurren a un similar propósito; (b) una armoniosa síntesis de dinamismo y estaticidad, de movilidad y concentración dramática en el tratamiento de las respectivas situaciones actanciales; y (c) una predominante focalización centralizadora del conflicto, que a menudo se desglosa en diferentes puntos de vista. O sea que lo que la articulación semiótica (sintáctica, semántica y pragmática) del texto "tutor" permite abducir, respecto de eventuales o futuras transducciones (teatrales, fílmicas, etc.), es una conceptualización a la vez sintética y sincrética de lo espectacular, que opera sin desmedro de una adecuada jerarquización e individualización del conflicto dramático, incluidas las recurrencias temáticas de su matriz contextual, aunque por momentos pareciera diluirse en dispersiones multiplicadoras. 
1.3. Dicha polidiscursividad escénica no sólo propicia lecturas e interpretaciones diversas (según específicas perspectivas teóricas y analíticas, algunas de las cuales procuré establecer), sino que además entrama e interrelaciona, de diferentes modos, la relación dinámica de los componentes sígnicos de la obra teatral analizada, con las instancias de producción y reconocimiento textual. En consecuencia, a las actividades básicas de $>$ expresión $>$ significación $>$ comunicación > interacción e > interpretación sígnica (que Bobes Naves en 1997 ha caracterizado atribuyendo funciones específicas a los distintos emisores y receptores participantes en cada instancia, conforme con un orden de sucesión que permite subsumir los anteriores), es posible agregar las operatorias propias de un proceso semiótico de transducción.

1.4. La nueva instancia receptora (transductora), en virtud de sus específicas competencias expresivas, comunicativas, etc., resignifica los interpretantes establecidos en el texto original, los desplaza o modifica, los transforma o les asigna otros sentidos, descubriendo o proponiendo posibilidades de nuevas lecturas, y materializando a la vez nuevos procesos de producción significante. Los tres recorridos analíticos practicados explicitaron su pertinencia descriptiva e interpretativa en procedimientos iniciales de segmentación. Con ellos se articularon dos propuestas poligonales de lectura, las que al reordenar el material analizado en función de recurrencias temáticas o formales, permiten conjeturar nuevos indicios problemáticos pero significativos de la referenciación ideológica e histórico-política del texto dramático de Eichelbaum. El señalamiento tópico final, a propósito de ciertas constantes significativas en las producciones fílmicas de Nilsson y Murúa, no sólo anticipan (en cada caso) una determinada recuperación crítica de diversos entramados significantes del texto original, sino que además propician una aproximación introductoria al posible tratamiento de ciertos mecanismos fílmicos de transducción semiótica de Un guapo del 900, los que habrán de profundizarse y desarrollarse (como queda dicho) en la etapa siguiente de la investigación en curso. 


\section{ANEXOS DEL INFORME}

\subsection{ESTRUCTURA DEL TEXTO DRAMÁTICO (DIAGRAMA)}

\begin{tabular}{|c|c|c|c|}
\hline ACTOS & CUADROS & $\begin{array}{l}\text { ESPACIOS } \\
\text { ESCÉNICOS }\end{array}$ & SITUACIONES DRAMÁTICAS \\
\hline \multirow[t]{2}{*}{$\mathbf{I}$} & 1 ro & $\begin{array}{l}\text { Almacén } \\
\text { de ramos } \\
\text { generales } \\
\text { en un } \\
\text { suburbio de } \\
\text { Buenos Aires }\end{array}$ & $\begin{array}{l}\text { Anticipación del conflicto e intercalación de escenas cotidianas [am- } \\
\text { bientación, costumbrismo] que amplían la caracterización del medio: } \\
\text { 1. Animado ritmo inicial, con diálogos sucesivos de tres acciones } \\
\text { paralelas: (a) don Pedro Lalanne, dueño del almacén, regatea con un } \\
\text { cliente la venta de una cincha; (b) Luciana, la hija, atiende a su amiga } \\
\text { Maruja; (c) Puentes Vila y Gualberto, dos parroquianos, discuten temas } \\
\text { de política [ref.contexto histórico] mientras esperan ser atendidos } \\
\text { 2. Sucesión y alternancia de situaciones, aumenta el ritmo vertiginoso } \\
\text { [Natividad, centro de la acción]: (a) entran Natividad, Palmero y El } \\
\text { Quebrao, que dialogan y beben mientras esperan a Ecuménico; (b) } \\
\text { Don Pedro atiende a un Chico; (c) Puentes y Gualberto retoman su } \\
\text { discusión política; (d) ingresa Pancho (hermano de Ecuménico) que } \\
\text { sostiene un diálogo afectivo con Luciana; (e) se retoman fragmentos } \\
\text { de conversaciones anteriores; ( } \mathrm{f} \text { ) despedida de Maruja; (g) se retira } \\
\text { Gualberto; (h) Puentes Vila traslada la discusión al grupo de Natividad } \\
\text { 3. Ingresan Ecuménico y Ladislao [el Guapo centraliza nuevas y } \\
\text { anteriores discusiones]; el enfrentamiento Palmero-Ecuménico de- } \\
\text { sencadena el conflicto escénico: su lealtad -ahora perturbada- al } \\
\text { Caudillo político pasa a primer plano y su sola presencia solidifica } \\
\text { el final del cuadro }\end{array}$ \\
\hline & 2do & $\begin{array}{l}\text { Habitación } \\
\text { de hotel } \\
\text { (reservado) }\end{array}$ & $\begin{array}{l}\text { 1. Encuentro amoroso entre Edelmira (mujer del Caudillo) y Clemente } \\
\text { Ordóñez (político en ascenso); [conversación estereotipada y cursi] } \\
\text { 2. Entrada de Ecuménico; provocación de Ordóñez; el Guapo lo } \\
\text { apu-ñala mortalmente; diálogo final con Edelmira y cierre del cuadro }\end{array}$ \\
\hline II & 3ro & $\begin{array}{l}\text { Comité } \\
\text { (despacho } \\
\text { del Caudillo) }\end{array}$ & $\begin{array}{l}\text { 1. Escenas costumbristas de comité en vísperas de elecciones (varie- } \\
\text { dad de enfoques y situaciones; diversa galería de personajes: desde } \\
\text { parasitarios hasta aprendices de guapo, pedigüeños o rutinarios } \\
\text { jugadores de naipes), con eje en Lauro, el encargado del comité } \\
\text { 2. Ingresa Alejo Garay; actitud dominante y ostentación de poder } \\
\text { en diversas situaciones fragmentarias; inquietud por la ausencia } \\
\text { del Guapo } \\
\text { 3. Entrada de Ecuménico; ríspida conversación a solas acerca del } \\
\text { asesinato de Ordóñez: clímax de la situación de enfrentamiento entre } \\
\text { el Guapo y el Caudillo, incluida su amenaza de denuncia; despedida }\end{array}$ \\
\hline
\end{tabular}




\begin{tabular}{|c|c|c|c|}
\hline & 4to & $\begin{array}{l}\text { Esquina de } \\
\text { suburbio }\end{array}$ & $\begin{array}{l}\text { Estampa de barriada porteña: reunión callejera en esquina de suburbio } \\
\text { 1. Animada conversación de compadritos y orilleros (carreras de ca- } \\
\text { ballos, etc.); regocijo por el relato de Gualberto (sobre paseo a San } \\
\text { Fernando); pasaje del organito; ritualidad en el baile de un tango } \\
\text { 2. Llega Natividad: nueva derivación al conflicto. Desplantes, amargu- } \\
\text { ra, desencanto por actitudes de amigos ante Ecuménico encarcelado }\end{array}$ \\
\hline \multirow[t]{2}{*}{ III } & 5to & $\begin{array}{l}\text { Mansión de } \\
\text { Alejo Garay } \\
\text { (escritorio) }\end{array}$ & $\begin{array}{l}\text { Visita a la casa del Caudillo para pedirle que interceda por su hijo } \\
\text { 1. Diálogo con Edelmira (su cobardía y defensa del estatus social) } \\
\text { 2. Entrevista (agitada, tempestuosa) con don Alejo: circunspección y } \\
\text { reticencias del Caudillo, angustia y actitud amenazante de Natividad }\end{array}$ \\
\hline & 6 to & $\begin{array}{l}\text { Casa de } \\
\text { Ecuménico } \\
\text { López } \\
\text { (habitación } \\
\text { de Natividad) }\end{array}$ & $\begin{array}{l}\text { 1. Entran Ecuménico (recién liberado -por falta de pruebas) y sus ami- } \\
\text { gos; después su hermano Ladislao. Bromas, chanzas, clima de festejo: } \\
\text { Año Nuevo inminente. Espera de la madre con inquieta impaciencia } \\
\text { 2. Núcleos fragmentarios de acción (entradas/salidas de personajes). } \\
\text { Reencuentro con Natividad: conmoción, sobriedad, expectación } \\
\text { 3. Natividad y Ecuménico a solas: confesión de su crimen, propósito } \\
\text { y decisión; intentos por disuadirlo, temor e imploración, catarsis final }\end{array}$ \\
\hline
\end{tabular}

\subsection{RELEVAMIENTO DE VERSIONES FíLMICAS (FICHAS TÉCNICAS Y ARTÍSTICAS)}

\begin{tabular}{|c|c|c|c|}
\hline FILMACIÓN AÑO & 1952 (inconclusa) & 1960 & 1971 \\
\hline Título & Un guapo del 900 & Un guapo del 900 & Un guapo del 900 \\
\hline Director & Lucas Demare & Leopoldo Torre Nilsson & Lautaro Murúa \\
\hline Productora & $s / d$ & Producciones Angel & Aica Producciones \\
\hline Adaptación & U. Petit de Murat & Eichelbaum y Torre Nilsson & Néstor Gaffet y Lautaro Murúa \\
\hline Estreno & -- & 17 Ago 1960 (G. Rex y otros) & 30 Set 1971 (Ambassador) \\
\hline \multicolumn{4}{|l|}{ PROTAGONISTAS } \\
\hline Alejo Garay & Guillermo Bataglia & Arturo García Buhr & Lautaro Murúa \\
\hline Ecuménico López & Pedro Maratea & Alfredo Alcón & Jorge Salcedo \\
\hline Natividad López & Milagros de la Vega & Lydia Lamaison & China Zorrilla \\
\hline Edelmira Garay & Nélida Bilbao & Elida Gay Palmer & Chunchuna Villafañe \\
\hline Clemente Ordóñez & Santiago Gómez Cou & Duilio Marzio & J.W. Martín \\
\hline \multirow[t]{5}{*}{ Elenco } & Elisardo Santalla & Jorge Villalba & Jorge Villalba \\
\hline & Lydia Quintana & Beto Pianola & Erika Wallner \\
\hline & Gregorio Cicarelli & Susana Mayo & Leonor Galindo \\
\hline & Luis Otero & Luis Otero & Raúl Lavié \\
\hline & Néstor Deval, y otros & Ovidio Fuentes, y otros & Arnaldo André, y otros \\
\hline
\end{tabular}




\begin{tabular}{|c|c|c|c|}
\hline $\begin{array}{l}\text { DEL EQUIPO } \\
\text { DE PRODUCCIÓN }\end{array}$ & & & \\
\hline Productores asociados & $s / d$ & J. Sires, Néstor Gaffet, etc. & N. Gaffet, A. Conesa, etc. \\
\hline Dirección fotográfica & Ricardo Younis & Ricardo Younis & Juan C. Desanzo \\
\hline Escenografía & Ricardo Conord & Oscar Lagomarsino & Miguel A. Lumaldo \\
\hline $\begin{array}{c}\text { Ambientación } \\
\text { y vestuario }\end{array}$ & $s / d$ & Oscar Lagomarsino & R. Zemborain y T. Tamanes \\
\hline Música & Lucio Demare & Atilio Stampone & Víctor Proncet \\
\hline
\end{tabular}

\section{BIBLIOGRAFÍA}

\subsection{CORPUS TEXTUAL ANALÍTICO}

Eichelbaum, S. (1940) Un guapo del 900, texto dramático. Buenos Aires: Sudamericana. Ed. 1952, prologada por B. Canal Feijoo.

$>$ Transposiciones fílmicas

1 > Producciones Ángel (1960) Un guapo del 900. Largometraje, 84', blanco y negro. Dirigido por Leopoldo Torre Nilsson (colección privada). Estrenada el 17 de agosto de 1960 en Cines Gran Rex, Gaumont y otros, Buenos Aires.

2 > Aica Producciones (1971) Un guapo del 900. Largometraje, 105', color. Dirigido por Lautaro Murúa (colección privada). Estrenada el 30 de septiembre de 1971 en el Cine Ambassador, Buenos Aires.

\subsection{REFERENCIAS BIBLIOGRÁFICAS}

Ahumada, R. (1975-6) Seminario de teatro argentino (mímeo). Apuntes de Cátedra: Facultad de Letras de la Universidad Católica de Santa Fe.

Bobes Naves, M. C. (1987) Semiología de la obra dramática. Madrid: Arco Libros. $2^{\mathrm{a}}$ ed., 1997.

Brecht, B. (1972) Escritos sobre teatro. Buenos Aires: Nueva Visión.

Brecht, B. (1980) Diarios. Barcelona: Crítica. 
Brizuela, M. (2003) Teatro: palabra en situación. Córdoba: Comunicarte Ed. Canal. Feijóo, B. (1952) Prólogo a cuatro piezas de Eichelbaum ("Un guapo del 900" y otras). Buenos Aires: Sudamericana.

Cattrysse, P. (1996) "Descriptive and normative norms in film adaptation". Cinémas 6: 167-88.

Cattrysse, P. (1997) "The Polysystem Theory and Cultural Studies". Canadian Review of Comparative Literature 24(1): 49-55.

Dôlezel, L. (1990) Poetica occidentale. Tradizione e progresso. Torino: Giulio Einaudi. Dubatti, J. (2009) Concepciones de teatro. Poéticas teatrales y bases epistemológicas. Buenos Aires: Colihue Universidad.

Ferrari, M. [ed] (2007) De la letra a la imagen. Narrativas posfranquistas en sus versiones fílmicas. Mar del Plata: FUDEM.

Godoy Froy, M. (1982) Introducción al teatro de Samuel Eichelbaum. Buenos Aires: Plus Ultra.

Greimas, A. (1989) Del sentido II. Ensayos semióticos. Madrid: Gredos.

Greimas, A. y Courtés, J. (1979) Semiótica. Diccionario razonado de la teoría del lenguaje. Trad. E. B. Aguirre y H. Campodónico Carrión. Madrid: Gredos. 2a ed. 1991. pp. 7-19. Ingarden, R. (1971) "Les fonctions du langage au théätre". Poétique, 8.

Maestro, J. (1994) La expresión dialógica en el discurso lírico. Pragmática y transducción. Universidad de Oviedo.

Mogni, F. (1963) “Conversación con Lautaro Murúa”. Tiempo de cine, año IV - Nro 16. Pérez Bowie, J. (2003) La adaptación cinematográfica de textos literarios. Salamanca: Plaza Universitaria.

Toro, F. de (1987) Semiótica del teatro: del texto a la puesta en escena. Buenos Aires: Galerna. $3^{\mathrm{a}}$ ed, 2009.

Torop, P. (2002) "Intersemiosis y traducción intersemiótica”. Cuicuilco, 25(9). México . Torre Nilsson, L. (1985) Torre Nilsson por Torre Nilsson. Selección y prólogo de J.M. Couselo. Buenos Aires: Fraterna.

Ubersfeld, A. (1989) Semiótica teatral. Madrid: Cátedra.

Villanueva, D. (1992) "Los marcos de la literatura española”, en Rico, F. [ed] Historia y crítica de la literatura española. Tomo IX. Barcelona: Crítica. Pp. 3-38. 


\subsection{BIBLIOGRAFÍA GENERAL}

\subsubsection{DE APOYO TEÓRICO Y METODOLÓGICO}

Textos de referencia bibliográfica citados en 3.2.

Aumont, J. y otros: Estética del cine. Espacio fílmico, montaje, narración, lenguaje. Buenos Aires: Paidós. $2^{\mathrm{a}}$ ed., 2008.

Bobes Naves, M.C. (2001) Semiótica de la escena. Madrid: Arco Libros.

De Marinis, M. (1997) Comprender el teatro: lineamientos de una nueva teatrología. Buenos Aires: Galerna.

Castagnino, R.H. (1974) Semiótica, ideología, teatro hispanoamericano contemporáneo. Buenos Aires: Nova.

Gaudreaul, A. y Jost, F. (1990) El relato cinematográfico. Cine y narratología. Barcelona: Paidós. $2^{a}$ ed., 2008.

Helbo, A. (1989) Teoría del espectáculo. El paradigma espectacular. Buenos Aires: Galerna.

Pavis, P. (2000) El análisis de los espectáculos. Teatro, mimo, danza, cine. Barcelona: Paidós.

Toro, F. de [Ed] (1990) Semiótica y teatro latinoamericano. Buenos Aires: Galerna. Villegas, J. (1991) Nueva interpretación y análisis del texto dramático. Canadá: Girol Books.

\subsubsection{SOBRE TEMAS DE INTERÉS O ÁREAS AFINES AL INFORME}

Aguilar, G.M. (1994) Los directores del cine argentino. Lautaro Murúa. Buenos Aires: CEAL.

Cruz, J. (1962) Samuel Eichelbaum. Buenos Aires: Ediciones Culturales Argentinas. Eco, U. (1986) "El signo teatral" en Gestos, 2. Noviembre 1986.

Ordaz, L. (1957) El teatro en el Río de la Plata. Desde sus orígenes hasta nuestros días. Buenos Aires: Leviatán.

Ordaz, L. (1968) "Madurez del teatro: Defilippis Novoa, Discépolo, Eichelbaum", en Historia de la literatura argentina, 3. Buenos Aires: CEAL. pp. 1009-32.

Sarlo, B. (2001) Tiempo presente. Notas sobre el cambio de una cultura. Buenos Aires: Siglo XXI. 
Publicaciones del Proyecto de Semiótica (Santa Fe: Ediciones UNL)

1991 / Literatura y espectáculo. La transposición (colección Producciones de Investigación).

2004-2009 / De signos y sentidos. Cuadernos del proyecto (publicación semestral), especialmente:

Vol. 3 (2005) Construcción de proyectos en investigaciones aplicadas.

Vol. 6 (2007) Narrativas de identidad e imaginarios en el discurso teatral rioplatense.

\subsubsection{OTROS TEXTOS CONSULTADOS}

Barletta, L. (1960) Viejo y Nuevo Teatro, crítica y teoría. Buenos Aires: Eurindia.

Casadevall, D. (1965) La evolución de la Argentina vista por el Teatro Nacional. Buenos Aires: Ediciones Culturales Argentinas.

Castagnino, R.H. (1968) Literatura dramática argentina. Testimonios nacionales (1717-1967). Buenos Aires: Pleamar.

Couselo, J.M. y otros (1992) Historia del cine argentino. Buenos Aires: CEAL.

Feldman, S. (1990) La generación del '60. Buenos Aires: Instituto Nacional de Cinematografía / Legasa.

Mahieu, A. (1974) Breve historia del cine nacional (1896-1974). Buenos Aires: Almazor. Martín, J.A. (1987) Diccionario de realizadores contemporáneos. Buenos Aires: Instituto Nacional de Cinematografía. 
